\title{
The impact of nutritional status on the outcomes of cancer patients such as mortality, survey and length of hospitalization in palliative care
}

\author{
Deniz Avcı®, Ali Çetinkaya $\odot$ \\ Department of Palliative Care, University of Health Sciences, Kayseri Training and Research Hospital, Kayseri, Turkey
}

DOI: $10.18621 /$ eurj.420153

\begin{abstract}
Objectives: The aim of this study was to determine the effects of nutritional status of the cancer patients in the palliative unit on some important outcomes such as mortality, hospitalization periods and survey.

Methods: The study was carried out through a retrospective review of 65 cancer patients who were treated at the palliative care center. The age and gender of the patients, the type of cancer, the place where they are referred to the palliative unit (from home or from the hospital), from which unit they came from (oncology, intensive care unit, other services), the length of stay, how long they lived after discharge, how long each patient lived after the palliative unit hospitalization day and the NRS-2002 scores were recorded.

Results: There was a statistically significant difference between the median hospital duration of the homebased patients and the median duration of hospital-based patients (11 [2-42] days versus 22 [2-180] days) $(p=$ 0.001 ). The mean survival time of the home-based patients was median 87.5 (2-323) days, while this was 9 (2$104)$ days in hospital-based patients $(p=0.017)$. While $29.5 \%(\mathrm{n}=13 / 27)$ of the patients coming from the house died in the palliative care center, it was $70.5 \%$ in the patients taken from the hospital $(p=0.002)$. The NRS-2002 scores of the cancer patients who were followed up at the palliative unit were correlated with the age of the patients $(\mathrm{r}=0.365, p=0.003)$.

Conclusions: We concluded that the patients who came to palliative care from home have better surveys than the ones came from the hospital.
\end{abstract}

Keywords: Palliative care, mortality, nutrition, NRS-2002

Received: May 1, 2018; Accepted: December 13, 2018; Published Online: January 30, 2019

$\mathbf{M}$ alnutrition can be described as "a decrease in physical and mental functions resulting from inadequacy of intake or irregular diet, loss of body composition (reduction in lean mass) and deterioration of body cell mass, and worsening of the clinical outcome of the disease" [1]. Malnutrition is an important cause of hospital mortality [2].

Although many methods are used, a single method of recognizing malnutrition alone has not yet been established. The most useful tests in malnutrition screening are Subjective Global Assessment (SGA), "Nutritional Risk Screening-2002 (NRS-2002)" and Mini-Nutritional Assessment (MNA) [3]. For hospitalized patients, the NRS-2002 test is a more appropriate screening method [4].

In recent years, intensive efforts have been made

Address for correspondence: Deniz Avcl, MD., University of Health Sciences, Kayseri Training and Research Hospital, Department of Palliative Care, Kayseri, Turkey 
to predict patients' return to home in palliative care units. Many factors in the past Meta-analyzes have been proposed as predictors. These include advanced age, mobility limitation, cognitive impairment, living alone, lower activities of daily living (ADL), male gender, medical needs and dysphagia [5-7]. In addition to these factors, nutritional factors were also investigated as factors affecting return to home. Parenteral nutrition has been reported to reduce home return [5]. In another study, it was reported that there was no significant relationship between home return and mininutritional assessment [8]. In a recent study, it was reported that survivals of cancer patients with better muscular strength were better.

The association of the NRS-2002 score with the mortality and morbidity of hospitalized patients has been demonstrated in previous studies [9-11]. In addition, the association of the NRS-2002 score with survival has also been demonstrated in a number of diseases such as metastatic cancer patients [12], congestive heart failure patients [13].

In this study, some parameters of cancer patients who were hospitalized in palliative unit were investigated according to nutritional status, including length of stay, survival time, return to home.

\section{METHODS}

The study was carried out through a retrospective review of 65 cancer patients who were treated at the Palliative Care Center of the University of Health Sciences, Kayseri Training and Research Hospital.

The age and gender of the patients, the type of cancer, the place where they are referred to the palliative unit (from home or from the hospital), from which unit they came from (such as oncology clinics, intensive care units and other services), the length of stay, how long they lived after discharge, how long each patient lived after the palliative unit hospitalization day and the NRS-2002 scores were recorded.When the patients were discharged, they were looked at from the official population system for how long they lived after discharge. Besides, total cholesterol, LDL, HDL and triglyceride values of the patients on admission day were recorded.

NRS-2002 Screening Tool
NRS-2002 is a nutritional screening method that uses parameters such as Body Mass Index (BMI), weight loss in the last 3 months, current serious diseases and age. Increases in the NRS-2002 scores indicate that patients have more nutritional risks [4]. The NRS-2002 screening is routinely performed on each patient in our palliative unit.

\section{Statistical Analysis}

The continuous data were analyzed with mean, standard deviation, median and percentages. Student's $t$ test was used to compare continuous variables between the groups. Mann-Whitney U test was used to compare median numerical variables with a skewed distribution. Chi-square test was used to compare categorical variables. Pearson correlation analysis was utilized to determine the relations between the patient and control groups. Kaplan-Meier survival analysis was used to estimate the frequency of death from high NRS-2002 score.A $p$ value of $<0.05$ was considered as significant. All statistical analyses were performed by using Statistical Package Program for Social Sciences 21.0 (Statistical Package for Social Sciences Inc., Chicago, Illinois).

Table 1. Distribution of cancer types in the group

\begin{tabular}{lc}
\hline CANCER TYPE & RATIO \\
\hline Colon cancer & $26.2 \%(\mathrm{n}=17)$ \\
Stomach cancer & $15.4 \%(\mathrm{n}=10)$ \\
Lung cancer & $20.0 \%(\mathrm{n}=13)$ \\
Pancreatic cancer & $9.2 \%(\mathrm{n}=6)$ \\
Cancer with unknown primary & $6.2 \%(\mathrm{n}=4)$ \\
site & \\
Renal cell carcinoma & $3.1 \%(\mathrm{n}=2)$ \\
Malign melanoma & $3.1 \%(\mathrm{n}=2)$ \\
Parotis gland cancer & $3.1 \%(\mathrm{n}=2)$ \\
Nasopharynx cancer & $3.1 \%(\mathrm{n}=2)$ \\
Ovarian cancer & $3.1 \%(\mathrm{n}=2)$ \\
Breast cancer & $3.1 \%(\mathrm{n}=2)$ \\
Basal cell cancer of the skin & $1.5 \%(\mathrm{n}=1)$ \\
Squamous cell cancer of the & $1.5 \%(\mathrm{n}=1)$ \\
skin & \\
Hepatocellular carcinoma & $1.5 \%(\mathrm{n}=1)$ \\
Duodenum cancer & $1.5 \%(\mathrm{n}=1)$ \\
\hline
\end{tabular}




\section{RESULTS}

There were a total of 65 cancer patients included in the study. The mean age of these patients was 66.86 \pm 13.9 years. Of these patients $63.1 \%(n=41)$ were female and $36.9 \%(n=36.9)$ were male. There were advanced cancer in all of them. The distribution of patients according to cancer types is given in Table 1 . The distribution of the patients according to the NRS2002 score on the application days is given in table 2 . There was severe malnutrition $(\geq 3)$ in $89.2 \%$ of the patients.

\section{Previous Place of the Patients Before Palliative Unit}

The distribution of the patient due to previous place is given in Table 3 . There was no statistically significant difference in terms of gender when the patients were divided into two groups as the ones coming from the house and the ones coming from the hospital $(p=0.225)$.

There was a statistically significant difference between the median hospital duration of the homebased patients and the median duration of hospital-based patients (11 [2-42] days versus 22 [2$180]$ days $)(p=0.001)$. Similarly, if the patients could

Table 2. NRS-2002 scores on the day of admission

\begin{tabular}{lc}
\hline NRS-2002 scores & Ratio \\
\hline $\mathbf{1}$ & $3.1 \%(\mathrm{n}=2)$ \\
$\mathbf{2}$ & $7.7 \%(\mathrm{n}=5)$ \\
$\mathbf{3}$ & $40.0 \%(\mathrm{n}=26)$ \\
$\mathbf{4}$ & $32.3 \%(\mathrm{n}=21)$ \\
$\mathbf{5}$ & $16.9 \%(\mathrm{n}=11)$ \\
\hline
\end{tabular}

Table 3. The distribution of the patient due to previous place

\begin{tabular}{lc}
\hline Patients' origin & RATIO \\
\hline Home & $43.1 \%(\mathrm{n}=28)$ \\
Oncology & $38.5 \%(\mathrm{n}=25)$ \\
Intensive Care Unit & $1.5 \%(\mathrm{n}=1)$ \\
Other services & $16.9 \%(\mathrm{n}=21)$ \\
\hline
\end{tabular}

be discharged, their post-discharge survival was more in favor of home-based patients. The mean survival time of the home-based patients was median 87.5 (2$323)$ days, while this was 9 (2-104) days in hospital-based patients $(p=0.017)$.

Although the lipid parameters of home-based patients differ from those of hospital-based patients, there is no statistical significance. The median LDL values of the home-based patients were 93 (47-223) $\mathrm{mg} / \mathrm{dL}$, which was 71 (20-139) mg / dL for hospitalbased patients $(p=0.069)$. While the median triglyceride values of home-based patients were 174 (41-227) $\mathrm{mg} / \mathrm{dL}$, this value was 110 (20-139) $\mathrm{mg} /$ $\mathrm{dL}$ in hospital-originated patients $(p=0.083)$.

While the median HDL values of home-based patients were 22 (15-64) $\mathrm{mg} / \mathrm{dL}$, this value was 27 (10-50) $\mathrm{mg} / \mathrm{dL}$ in patients coming from the hospital $(p=0.221)$. The mean serum albumin level of the home-based patients was $2.73 \pm 0.57 \mathrm{mg} / \mathrm{dL}$, which was $2.57 \pm 0.56 \mathrm{mg} / \mathrm{dL}$ in hospital-based patients ( $p$ $=0.266)$. While $29.5 \%(n=13 / 27)$ of the patients coming from the house died in the palliative care center, the death rate in the palliative care center of the patients taken from the hospital was $70.5 \%$ ( $\mathrm{n}=$ 31/37). The difference between these two ratios was statistically significant $(p=0.002)$.

Although the NRS-2002 values were better for the patients from the home, the difference between the median NRS-2002 scores of home-based cancer patients and those taken over from hospital services was not statistically significant $(3.0$ [1-5] versus 3.58 $[1-5]),(p=0.675)$.

\section{Distribution of Patients According to Their Place of Death}

Forty-four $(68.8 \%)$ patients died at the palliative unit. Twenty $(31.3 \%)$ were discharged from the palliative unit. When the study was over, 1 patient was still being followed in the palliative unit. Of the 20 discharged patients, 17 died at home and 3 were still alive. In total, 61 of 65 patients eventually died.

\section{Place of Death and Gender}

Distribution of deaths by gender did not show any statistical difference. Sixteen (69.6\%) female patients died at the palliative unit. In males this rate was $68.7 \%$ $(\mathrm{n}=28 / 41)(p=0.916)$. There were no statistically significant differences in terms of hospital stay, 


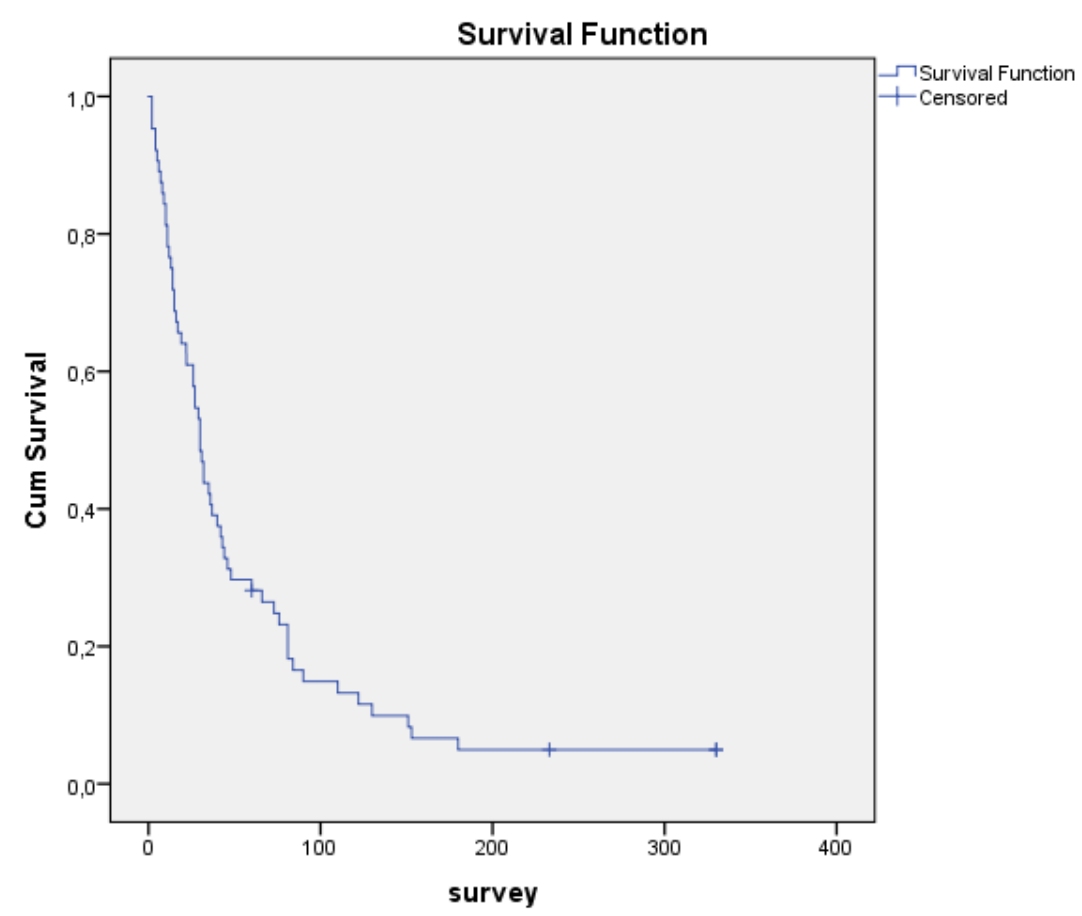

Figure 1. Survival functions of 65 cancer patients those hospitalized in palliative care.

survival from first admission to the palliative unit, and survival after discharge from the palliative unit in terms of gender ( $p$ values of $0.856,0.886$ and 0.575 , respectively).

\section{NRS-2002 and Gender}

NRS-2002 scores of the patients did not differ between sexes. The median NRS-2002 score in male gender was 4 (1-5) while in female gender this score was 3 $(2-4)(p=0.139)$.

\section{Correlation Analysis}

The NRS-2002 scores of the cancer patients who were followed up at the palliative unit were significantly correlated with the age of the patients at the mild level $(\mathrm{r}=0.365, p=0.003)$. There was no statistically significant correlation between NRS-2002 score and hospital stay $(\mathrm{r}=-0.147, p=0.246)$. There was no statistically significant correlation between the NRS2002 score and survival after admission to the palliative unit $(\mathrm{r}=-0.237, p=0.061)$. There was no correlation between NRS-2002 scores and serum albumin levels $(\mathrm{r}=-0.159, p=0.205)$.

\section{Survival Analyses}

Only $61 / 65$ patients were alive when the study was completed. On the 15th day after admission to the palliative unit, only $75 \%$ of the patients were alive. On the thirtieth day, this rate had fallen to $48 \%$. On day 73 , the survival rate was $25 \%$. At 180 days this rate was around $3 \%$ (Figure 1).

In 65 patients who were hospitalized in the Palliative care unit, Kaplan-Meier plots demonstrated that there was a no significance in survival between cancer patients who had NRS-2002 score $\geq 3$ or $<3$ on admission (Figure 2).

\section{DISCUSSION}

According to ESPEN guidelines, there should now be an approach to nutritional support, continuity and frequent reassessment of patients at the end of life. The effects of nutritional status on mortality have been studied in many disciplines. However, in fact, the main goals are not much different from an acute malnutrition treatment [14].

In a study conducted last month, some results were obtained that some predictors in palliative care centers (PBM) may affect the length of hospitalization. According to this, the conditions that increase the length of stay in the hospital are as follows: cancer, 


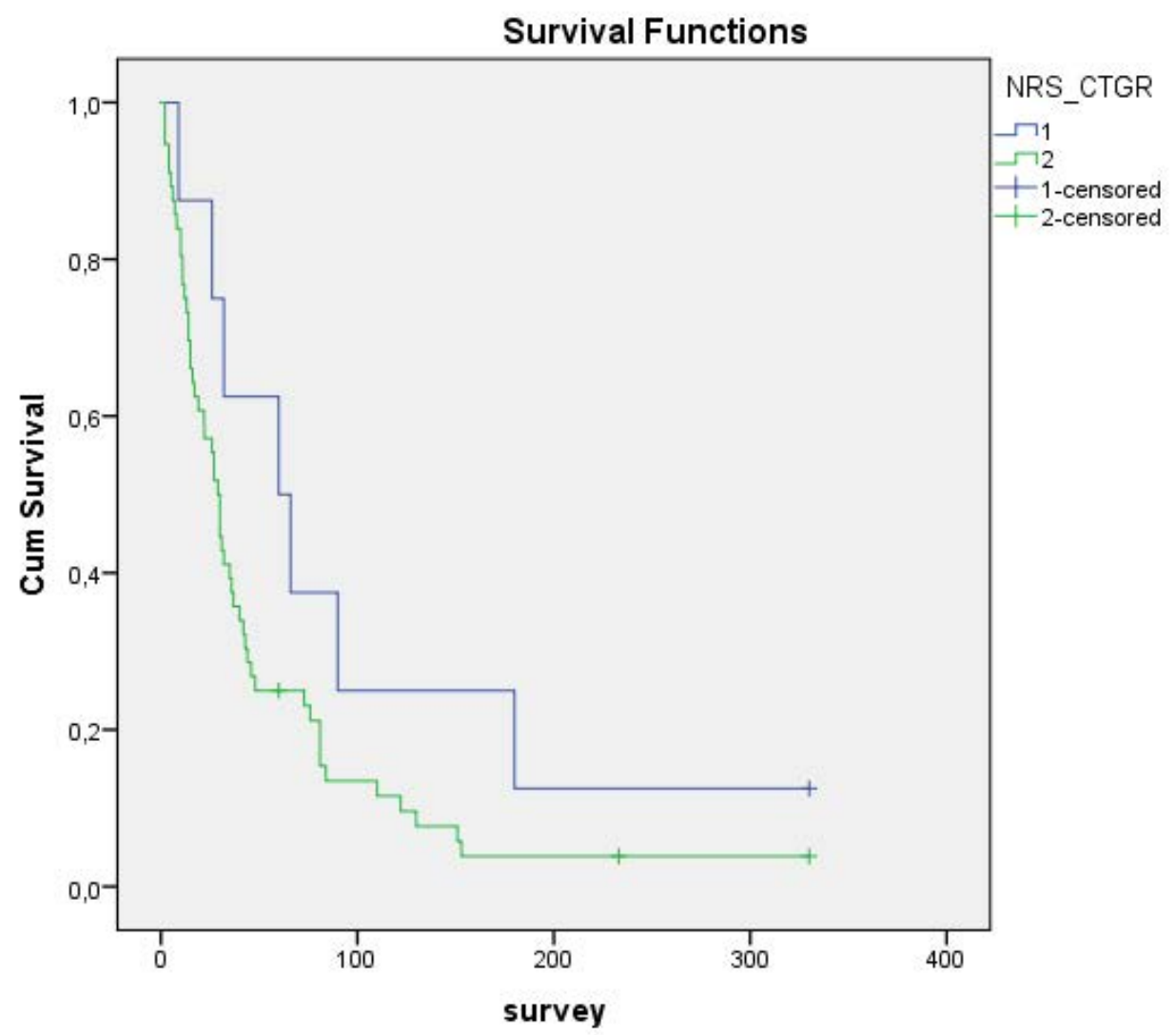

Figure 2. Kaplan-Meier Plots demonstrating Survival of Patients. Kaplan-Meier survival analysis demonstrated a longer hospital survival in cancer patients with Nutritional Risk Screening 2002 (NRS 2002) score <3 compared with patients who had NRS 2002 score $\geq 3$ on admission to the palliative unit, but there is no statistical significance $(p=0.127)$.

hypoxic brain, elderly patients are affected negatively; Infection causes such as PEG (percutaneous endoscopic gastrostomy), total parenteral nutrition (TPN); chronic diseasessuch as hypertension and agents such as E. coli, proteus, Pseudomonas and Acynetobacter affect long hospital stay [15]. Another study, which was published a few months ago, emphasized that the median survival in significant malnutrition end-stage cancer patients was significantly reduced [16]. Decreased phase angle is positively correlated with nutrition of end stage cancer patients in palliative care. Decreased phase angle indicates decreased survival [17].

A weight loss of $\geq 5 \mathrm{~kg}$ in patients receiving palliative chemotherapy has been shown to significantly reduce survival [18]. Inanother research, it was concluded that a weight loss of $\% 10$ of total body weight is related with a worsened survival [19].

In the present study, a number of parameters were examined, including nutrition scores, length of hospital stay, and length of life after discharge, and dischargeability of 65 end-stage cancer patients. NRS2002 scores were $\geq 3$ in almost $90 \%$ of patients who received PBM. The age of the patients followed in the palliative unit and the NRS-2002 scores were mildly and significantly correlated in positive direction.

Home-based patients had a significantly longer hospital stay. It should be noted that terminal cancer patients often die in PBM, so it is not wrong to say that patients with longer hospitalization times are in better condition. This may be due to the fact that home-based patients may be relatively far away from terminal. It is highly probable that the patients taken from the hospital have spent this period in other services. Similarly, median survival times after discharge from home-based patients were significantly higher than those from hospital. It may be possible to link this to the same reasons.

As is known, serum triglyceride levels are inversely proportional to survival in critically ill patients [20]. In this group, the serum triglyceride levels of the patients from the home were 174 (41-227) 
$\mathrm{mg} / \mathrm{dL}$, which were $110(20-139) \mathrm{mg} / \mathrm{dL}$ in patients coming from the hospital. Serum LDL levels were also higher in favor of the patients coming from the home. Serum LDL levels were median 93 (47-223) mg / dL in patients coming from the home, while this value was 71 (20-139) $\mathrm{mg} / \mathrm{dL}$ in patients coming from the hospital. There was no statistical significance here, but it could be changed by increasing the number. We attributed the LDL level to be higher in favor of the patients from the home to better nutritional performance of the patients them. There was no statistical difference in serum HDL and albumin levels.

The outcome of death in patients admitted to the palliative unit from the home was also statistically significantly lower than in patients admitted to the hospital. $29.5 \%(n=13 / 27)$ of the patients coming from home died in the palliative care center while $70.5 \%(n=31 / 37)$ of the palliative care center of the patients taken from the hospital died. The difference between these two ratios was statistically significant. The difference was not statistically significant between the median NRS-2002 score of 3 (1-5) patients who were admitted from home and the NRS2002 scores of $3.58(1-5)$ of the patients from hospital services.

\section{CONCLUSION}

Both palliative care and nutrition are concepts that are of importance in recent times and seem to be in strong interaction with each other. In addition to this study showing that the nutritional status is important in the prognosis of the palliative care patient, it is also true that the nutrition in the palliative care is directly related to the prognosis of terminal cancer patients. We concluded that the patients who come to palliative care from home have better surveys than the ones from the hospital.

\section{Conflict of interest}

The authors disclosed no conflict of interest during the preparation or publication of this manuscript.

\section{Financing}

The author disclosed that they did not receive any grant during conduction or writing of this study.

\section{REFERENCES}

[1] Sobotka L, editor. Basics in clinical nutrition. 4th ed. Galen; 2012.

[2] Sieber CC. Nutritional screening tools--How doesthe MNA compare? Proceedings of the session held in Chicago May 2-3, 2006 (15 Years of Mini Nutritional Assessment). J Nutr Health Aging 2006;10:488-94.

[3] Bauer JM, Vogl T, Wicklein S, Trögner J, Mühlberg W, Sieber CC. Comparison of the Mini Nutritional Assessment, Subjective Global Assessment, and Nutritional Risk Screening (NRS 2002) for nutritional screening and assessment in geriatric hospital patients. Z Gerontol Geriatr 2005;38:322-7.

[4] Whitby LG. Screening for disease: definitions and criteria. Lancet 1974;2:819-22.

[5] Hakkarainen TW, Arbabi S, Willis MM, Davidson GH, Flum DR. Outcomes of patients discharged to skilled nursing facilities after acute care hospitalizations. Ann Surg 2016;263:280-5.

[6] Massucci M, Perdon L, Agosti M, Celani MG, Righetti E, Recupero E, et al. Prognostic factors of activity limitation and discharge destination after stroke rehabilitation. Am J Phys Med Rehabil 2006;85:963-70.

[7] Chang FH, Ni P, Jette AM. Does activity limitation predict discharge destination for post-acute care patients? Am J Phys Med Rehabil 2014;93:782-90.

[8] Guigoz Y. The Mini Nutritional Assessment (MNA) review of the literature - What does it tell us? J Nutr Health Aging 2006;10:466-85.

[9] Mercadal-Orfila G, Lluch-Taltavull J, Campillo-Artero C, Torrent-Quetglas M. Association between nutritional risk based on the NRS-2002 test and hospital morbidity and mortality. Nutr Hosp 2012;27:1248-54.

[10] Carvalho CS, Souza DS, Lopes JR, Castanho IA, Lopes AJ. Relationshipbetweenpatient-

generatedsubjectiveglobalassessmentandsurvival in patients in palliativecare. Ann Palliat Med 2017;6(Suppl 1):S4-S12.

[11] Nie R, Yuan S, Chen S, Chen X, Chen Y, Zhu B, et al. Prognostic nutritional index is an independent prognostic factor for gastric cancer patients with peritoneal dissemination. Chin J Cancer Res 2016;28:570-8.

[12] Zhou X, Qiu G, Bao W, Zhang D-H. The prognostic role of nutrition risk score (NRS) in patients with metastatic or recurrent esophageal squamous cell carcinoma (ESCC). Oncotarget 2017;8:77465-73.

[13] Tevik K, Thürmer H, Husby MI, de Soysa AK, Helvik AS. Nutritional risk is associated with long term mortality in hospitalized patients with chronic heart failure. Clin Nutr ESPEN. 2016;12:e20-e29.

[14] Druml C, Ballmer PE, Druml W, Oehmichen F, Shenkin A, Singer P, et al. ESPEN guideline on ethical aspects of artificial nutrition and hydration. Clin Nutr 2016;35:545-56.

[15] Dincer M, Kahveci K, Doger C. An examination of factors affecting the length of stay in a palliative care center. J Palliat Med 2018;21:11-5.

[16] Carvalho CS, Souza DS, Lopes JR, Castanho IA, Lopes AJ. Relationship between patient-generated subjective global assessment and survival in patients in palliative care. Ann Palliat 
Med. 2017;6(Suppl 1):S4-S12

[17] Kumar S, Dutt A, Hemraj S, Bhat S, Manipadybhima B. Phase angle measurement in healthy human subjects through bioimpedance analysis. Iran J Basic Med Sci 2012;15:1180-4.

[18] Buskermolen S, Langius JA, Kruizenga HM, Ligthart-Melis GC, Heymans MW, Verheul HM. Weight loss of 5\% or more predicts loss of fat-free mass during palliative chemotherapy in patients with advanced cancer: a pilot study. Nutr Cancer
2012;64:826-32.

[19] Zacharakis M, Xynos ID, Lazaris A, Smaro T, Kosmas C, Dokou A, et al. Predictors of survival in stage IV metastatic colorectal cancer. Anticancer Res 2010;30:653-60.

[20] Cetinkaya A, Erden A, Avci D, Karagoz H, Karahan S, Basak $\mathrm{M}$, et al. Is hypertriglyceridemia a prognostic factor in sesis? Ther Clin Risk Manag 2014;10:147-50. 